\title{
ON TWIN EDGE COLORINGS OF GRAPHS
}

\author{
Eric Andrews, LaArs Helenius \\ Daniel Johnston, Jonathon VerWys
}

AND

PING ZHANG

Department of Mathematics Western Michigan University

Kalamazoo, MI 49008, USA

e-mail: ping.zhang@wmich.edu

\begin{abstract}
A twin edge $k$-coloring of a graph $G$ is a proper edge coloring of $G$ with the elements of $\mathbb{Z}_{k}$ so that the induced vertex coloring in which the color of a vertex $v$ in $G$ is the sum (in $\mathbb{Z}_{k}$ ) of the colors of the edges incident with $v$ is a proper vertex coloring. The minimum $k$ for which $G$ has a twin edge $k$-coloring is called the twin chromatic index of $G$. Among the results presented are formulas for the twin chromatic index of each complete graph and each complete bipartite graph.
\end{abstract}

Keywords: edge coloring, vertex coloring, factorization.

2010 Mathematics Subject Classification: 05C15, 05C70.

\section{REFERENCES}

[1] L. Addario-Berry, R.E.L. Aldred, K. Dalal and B.A. Reed, Vertex colouring edge partitions, J. Combin. Theory (B) 94 (2005) 237-244. doi:10.1016/j.jctb.2005.01.001

[2] M. Anholcer, S. Cichacz and M. Milanič, Group irregularity strength of connected graphs, J. Comb. Optim., to appear. doi:10.1007/s10878-013-9628-6

[3] G. Chartrand, M.S. Jacobson, J. Lehel, O.R. Oellermann, S. Ruiz and F. Saba, Irregular networks, Congr. Numer. 64 (1988) 187-192. 
[4] G. Chartrand, L. Lesniak and P. Zhang, Graphs \& Digraphs: 5th Edition (Chapman \& Hall/CRC, Boca Raton, FL, 2010).

[5] G. Chartrand and P. Zhang, Chromatic Graph Theory (Chapman \& Hall/CRC, Boca Raton, FL, 2008). doi:10.1201/9781584888017

[6] J.A. Gallian, A dynamic survey of graph labeling, Electron. J. Combin. 16 (2013) \#DS6.

[7] R.B. Gnana Jothi, Topics in Graph Theory, Ph.D. Thesis, Madurai Kamaraj University (1991).

[8] S.W. Golomb, How to number a graph, in: Graph Theory and Computing R.C. Read (Ed.), (Academic Press, New York, 1972) 23-37.

[9] R. Jones, Modular and Graceful Edge Colorings of Graphs, Ph.D. Thesis, Western Michigan University (2011).

[10] R. Jones, K. Kolasinski, F. Fujie-Okamoto and P. Zhang, On modular edge-graceful graphs, Graphs Combin. 29 (2013) 901-912. doi:10.1007/s00373-012-1147-1

[11] R. Jones, K. Kolasinski and P. Zhang, A proof of the modular edge-graceful trees conjecture, J. Combin. Math. Combin. Comput. 80 (2012) 445-455.

[12] M. Karoński, T. Luczak and A. Thomason, Edge weights and vertex colours, J. Combin. Theory (B) 91 (2004) 151-157.

doi:10.1016/j.jctb.2003.12.001

[13] A. Rosa, On certain valuations of the vertices of a graph, in: Theory of Graphs, Proc. Internat. Symposium Rome 1966 (Gordon and Breach, New York 1967) 349-355.

[14] V.G. Vizing, On an estimate of the chromatic class of a p-graph, Diskret. Analiz. 3 (1964) 25-30 (in Russian).

Received 19 July 2013

Revised 13 September 2013

Accepted 16 September 2013 